\title{
Credited information literacy training sessions for graduate students, still relevant after 18 years: A case study
}

\section{Elise Anne Basque, Ecole Polytechnique de Montreal}

Elise Anne Basque has been a Science and Engineering Librarian at Polytechnique Montréal since 2011. She holds a B.Sc. in mathematics and a Master's degree in Information Science from Université de Montréal, and a B.Ed. in education from University of Ottawa. At the Polytechnique Library, she specializes in mathematics, statistical data, biomedical engineering, and physics engineering. She is involved in information literacy workshops and bibliometrics.

\section{Christine Brodeur, Polytechnique Montréal}

Christine Brodeur holds a bachelor's degree in education and science from McGill University, in Montréal. She taught high school for 6 years before enrolling at Université de Montréal to complete a Master of Information Sciences. She has been working as a librarian at Polytechnique Montréal since 2013, doing a variety of tasks, with a focus on bibliometrics and teaching information literacy.

\section{Manon Du Ruisseau, Ecole Polytechnique de Montreal}

Manon Du Ruisseau has been working at the Polytechnique Montréal Library for more than 30 years. During the first years of her career, she worked as a library technician and since then she occupied various positions that allowed her to explore all aspects of library services. In 2000, she obtained her Master of Library and Information Science from the Université de Montréal and has been working as a librarian ever since. In 2012, she became Section Head of the Information Consulting Services.

\section{Mr. Jimmy Roberge, Ecole Polytechnique de Montreal}

Jimmy Roberge has been working as a Science and Engineering Librarian at Polytechnique Montréal's Library since 2017. He completed his M.S.I. in Information Science (in 2016) and a Short Graduate Program in Teaching at the Post-secondary Level (in 2014), both at Université de Montréal. Prior to 2013, he received his B.A. in Geography from Université Laval and his M.Env. in Environment from Université de Sherbrooke, and worked for a consulting engineering firm for seven years as an environmental consultant.

\section{Mrs. Arina Soare, Ecole Polytechnique de Montreal}

A former engineer, Arina Soare changed careers and obtained her M.L.I.S. degree from McGill University in 2011. Since then, she has been working as a Science and Engineering librarian at Polytechnique Montreal, helping students improve their research skills. She specializes in mechanical, aerospace, computer, and electrical engineering and provides instruction in Research Methods graduate workshops in a diverse environment. She conducts workshops and provides assistance and support on EndNote and BibTeX to students and faculty.

\section{Mrs. Marie Tremblay, Ecole Polytechnique de Montreal}

Marie Tremblay has a Master's degree in Information Science from Université de Montréal. She works as a Science and Engineering Librarian at Polytechnique Montréal since 2015, and previously worked in a hospital library. She is interested in the accessibility of information and the roles of the library within an engineering educational institution. Prior to her work as a librarian, she earned a B.A. in French Linguistics and a M.A. in Translation and spent nearly 15 years working as a translator and reviser. 


\title{
Credited Information Literacy Training Sessions for Graduate Students, Still Relevant After 18 Years: A Case Study
}

\begin{abstract}
This case study focuses on the mandatory and credited information literacy training sessions offered by a team of librarians since 2002 to more than 5000 graduate students enrolled in a research program at a francophone engineering university. Their creation was justified in part by a survey in which many professors mentioned they would like their students to develop better information research skills. This paper describes how these sessions have evolved since their implementation and discusses the factors that contributed to their continuation over time.

Initially, these training sessions were mandatory for all PhD students. In 2008, they also became mandatory for all research master's students. Due to the significant increase in the number of students attending these sessions, important changes were made to the type of learning assessment. At first, the students were required to produce a portfolio related to their research projects that the librarians graded and to which they suggested ways of improvement. This evaluation method being time-consuming, it was changed to open-book exams. After a few years, the librarians decided to modify the assessment again to allow students to work on their own projects. Moreover, a heterogeneous clientele posed some significant challenges. For example, the university has welcomed a growing international graduate student population that did not speak French. In response to these challenges and to institutional requests, the team of librarians started offering classes in both English and French in 2010, and integrated more active pedagogies. Throughout these transformations, the University's senior leadership always approved the proposed changes and maintained the mandatory information literacy training.
\end{abstract}

Students participating in the training sessions filled teaching evaluation surveys, for which the results are presented in this paper. The surveys asked the students about their degree of satisfaction regarding the different objectives of the training sessions, namely defining an information need, building and optimizing a search strategy, finding information sources relevant to their field, and learning how to ethically use information. The surveys also asked whether sufficient time was allocated to reach the objectives and whether the students generally improved their information research skills. Overall, the results show a satisfaction rate of over $90 \%$ since 2011 for all evaluated criteria. In addition, creating and executing a search strategy in specialized databases is among the most common answers to an open-ended question about the most important thing the students learned.

The discussion section argues that the high satisfaction rates, the adjustments made to cater to the evolving needs of the clientele, and the compliance to the institutional requests contributed to maintaining the information literacy training sessions in the graduate programs. Positive effects include the librarians' professional development and an increased visibility for the Library 
resources and services. It also discusses the positive impact on the students' research skills and on their literature reviews. Consequently, the training sessions contribute to achieving the University learning objectives for graduate students in research programs. Introduction

\section{Introduction}

Founded in Montreal in 1873, Polytechnique Montréal is a francophone engineering university offering more than 120 academic programs. In Fall 2019, the institution had 9,000 students enrolled, with more than 2,200 in a graduate program [1]. Polytechnique Montréal strongly encourages diversity among its student population, so as of Fall 2019, 28\% of its students were women and 29\% were international students. Moreover, international students represented 50\% of Master's students and 78\% of PhD students [2].

For many years now, the need for enhancing information literacy (IL) training in universities has been well documented. It has been nearly 20 years since Polytechnique Montréal introduced in its academic curriculum a mandatory and credited IL course for graduate students. This course was created and updated with guidance from the Association of College \& Research Library (ACRL), most notably the Information Literacy Competency Standards for Higher Education [3] and the Framework for Information Literacy for Higher Education [4].

The main objectives of this paper are to describe the evolution of the course and to discuss the factors that have contributed to its success. An analysis of the results of students' satisfaction surveys is also presented, as well as a discussion of the most significant impacts that this course has had on students, research groups, the institution, and the Library staff.

\section{Review of the Literature}

The libraries' and librarians' role in information literacy training is well established in the literature. The concept of information literacy appeared in the 1970s and, in the 1990s, the academic libraries started to integrate this concept into the instruction delivered to students [5]. To do so, they based their instruction program on the definition proposed in 1989 by the American Library Association (ALA): "To be information literate, a person must [...] have the ability to locate, evaluate and use effectively the needed information" [6]. From this point, IL became more and more integrated into instruction offered by libraries, including for engineering students [5, 7], allowing universities to train lifelong learners who "know how to learn" [6].

Literature shows that IL instruction has evolved over the years. In the 1990s, the training sessions offered by librarians were commonly known as "bibliographic instruction" and were often based on workbooks $[8,9]$. At the turn of the millennium, they became known as "IL instruction" and increasingly took into account the presence of the Internet and its influence on information dissemination [3, 4]. Since 2010, IL instruction has been integrating a more conceptual approach, to the point that many academic librarians now "believe that 'understanding some ethical, legal, economic, and socio-political information issues' is an 
element of IL" [9]. This approach is reflected in the ACRL's Framework for Information Literacy for Higher Education [4].

IL instruction for graduate students takes various forms. It can be integrated into a graduate course or delivered as a stand-alone workshop. It can also be offered as a one-shot session or as a series of sessions. The latter offers the opportunity to establish a relationship with students, compared to the one-shot session, and appears to have a much greater impact on student retention $[9,10]$. The course-integrated sessions have the advantage of strengthening the links between librarians and professors and are directly related to the course content [10]. However, this approach may be less beneficial at the graduate levels, as each student works on a different topic. In such cases, training that is more generalized in terms of information retrieval and more personalized in terms of literature review development could be a better option [10].

A few studies conducted in the last ten years focused on the self-reported needs of graduate students. They showed that these students wanted to learn techniques to search and retrieve information in databases, to evaluate this information, to manage their references, and to stay current $[11,12]$. Students preferred to access information online, so it is important to teach them tips to search on the Internet $[12,13]$. Also, some graduate students have reported knowing general databases, but were less likely to know specialized databases [13]. Finally, graduate students need general information about the library as soon as they start their program, but also find it helpful to have instruction targeting their more specific information needs based on their research project.

Another factor to consider when establishing the more specific needs of graduate students is that there is a great disparity between graduate students concerning IL skills depending on their prior experience with library resources $[11,14]$. There might also be an erroneous perception that graduate students are more likely to have developed the required IL competency during their undergraduate studies $[15,16]$. Additionally, since graduate students usually form a more heterogeneous cohort than undergraduate students, librarians would be wise to adapt their instruction to this reality.

The outcomes of IL instruction on students and academic institutions have been documented in several studies, although research seems to be more focused on undergraduate students than on graduate students. In recent years, research has documented that IL instruction may be linked to various potential effects on graduate students. In a synthesis of the literature focusing on doctoral students, Harris identified doctoral attrition as a widespread problem in American universities [10]. Citing Dyckman [17], Harris mentions that the lack of basic IL knowledge among doctoral students may lead to difficulties in formulating a sound research question, failure to quickly and successfully find information on a topic, and a sentiment of incompetence and discouragement. Another study reports that providing IL instruction to doctoral students contributes to an increased confidence or efficacy in their search for information [18]. Similar effects have been observed with undergraduate students in engineering programs [19]. Several other studies have shown a correlation between participation in some format of IL instruction and student retention or re-enrollment rates in undergraduate programs [20,21].

It is also worth mentioning that IL instruction developed in collaboration with faculty provides important benefits for the library. Cultivating good relations with faculty is likely to generate 
more visibility for the library, as well as potential implications in departmental affairs. For example, Clairoux mentions that such a collaboration with faculty has resulted in a librarian being invited to join the curriculum renewal evaluation committee. The presence of a librarian in the committee is likely to increase the importance of IL instruction in the program's objectives and content [22].

In the light of what has been mentioned before, it seems that changes are inevitable when it comes to IL instruction. During the last 20 years, teaching librarians at Polytechnique Montréal have shown that they are able to adapt to the changing needs of its community, as demonstrated in the evolution of the mandatory and credited IL course for graduate students.

\section{Timeline: First Information Literacy Course for PhD Students Is Offered by the Library (Fall 2002)}

The course was created following the École Polytechnique's Action Plan 1999-2003 that included the specific objective of "providing students and researchers with training in bibliographic research" $[23,24]$. In addition, some professors, who had noticed the positive impact of the Library IL training at the undergraduate level, requested similar training for graduate students [24]. Moreover, the rapid development of specialized bibliographic databases led to an increase in the number of reference questions received at the Library, even though the engineering students were accustomed to using information technology [24].

Figure 1 shows the evolution of IL training sessions since 2001. The following paragraphs provide more details on the history of IL training at Polytechnique Montréal, including the main decisions that have supported and maintained it for so many years.

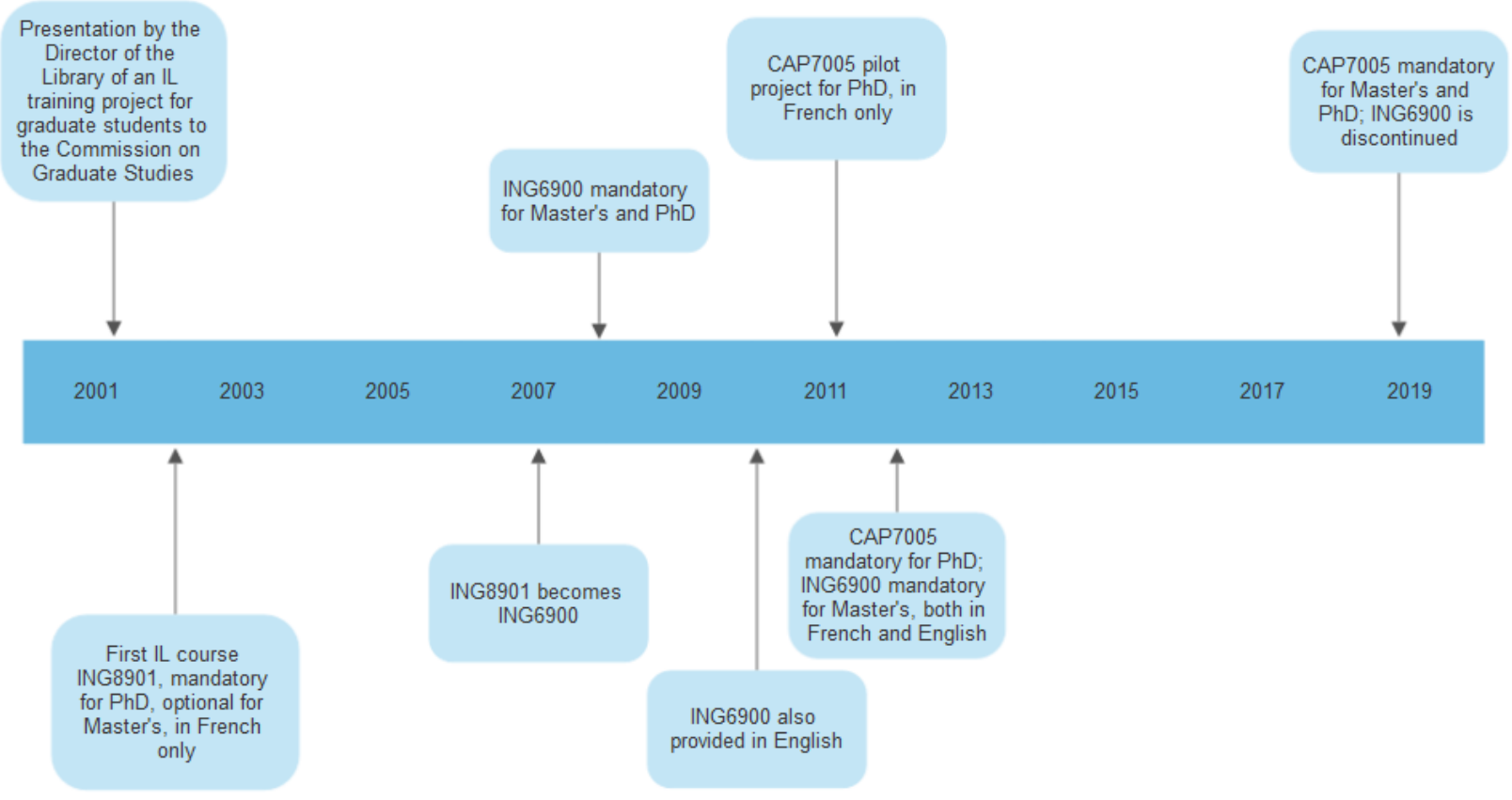

Figure 1. Milestones of IL credited training sessions, Polytechnique Montréal, 2001-2019 
On November 20, 2001, the Director of the Library presented to the Commission on Graduate Studies an IL training project for graduate students, based on the ACRL's Information Literacy Competency Standards for Higher Education [3] and supported by the Graduate Student Association, the Pedagogical Support Office, and the Graduate Studies Office [24].

The Library participation in the one-credit ING8901 Research Methods course (given in French only) began in September 2002 as a collaboration with the two professors in charge of the course. The professors were responsible for the lectures, whereas the Library was to conduct six two-hour laboratories as part of the course and to grade $50 \%$ of the credit. ING8901 was mandatory for PhD students, yet Master's students could also attend the course.

The main objectives of the laboratories were:

- to define information needs;

- to build and optimize a search strategy;

- to find information sources relevant to one's research field;

- to respect copyright and to avoid plagiarism; and

- to manage references using bibliographic management software.

To help the students produce their literature review, the ING8901 laboratories assessment consisted of grading an individual portfolio based on the particular research topic of each student, including a conceptual plan and a complex search strategy executed in databases such as Compendex, Inspec, and Web of Science. This portfolio determined whether the students had acquired the IL skills needed at the PhD level. The four librarians involved in the laboratories spent a large part of their time - about three hours per student - conducting a highly personalized and criteria-based assessment of about 65 students' portfolios per term.

At the time, Polytechnique Montréal predominantly welcomed French-speaking graduate students. However, over the years, more and more international students speaking little or no French and English as a second language (ESL) were required to enroll in the Research Methods course. To meet their needs, the librarians translated the laboratories materials into English.

Despite the fact that students found the workload heavy, the impact of the laboratories was noticed straight away by the course coordinators and by some research advisors. One of the coordinators even claimed that the course and the laboratories could reduce the time to complete a PhD by 3 to 6 months. Although no formal study on the contribution of the laboratories had been conducted, some students reported that the quality of their bibliographies in their dissertations or theses was noted by their research advisors or by other faculty members.

\section{Timeline: ING6900 Becomes Mandatory for Research Master's Students (Fall 2007) and Is} Later Offered in English (2010)

In Fall 2007, the Teaching and Learning Directorate decided that ING8901 would become ING6900. To support the quality of research and reduce the duration of the students' studies, it was decided, at the same time, to make the course mandatory for students in Master's research programs starting in Fall 2008. 
As it was anticipated that one hundred more students would enroll in the course in Fall 2008 (see Figure 2), the librarians decided to reduce the time allocated to assessment in order to comply with Polytechnique guidelines regarding grading time and to be able to continue to perform other tasks besides IL training.

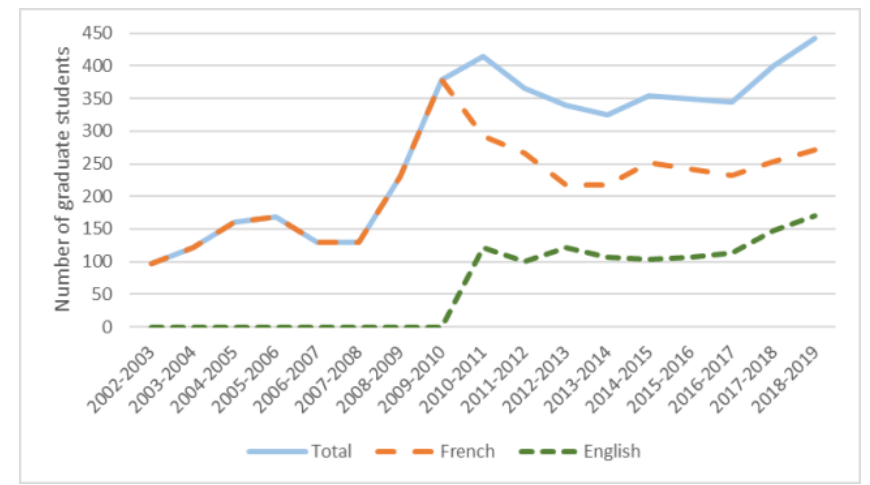

\section{Figure 2. Number of graduate students enrolled in credited IL sessions} per academic year, by language and in total

Consequently, the portfolio was replaced with two open-book exams, one midterm and one final. For the benefit of international students, the exams were available in French and in English. While grading the portfolios, the librarians noticed that some students did not have appropriate language proficiency. This was later confirmed by their difficulty understanding the exam questions.

Concerning the laboratories contents, the librarians reduced the time spent presenting EndNote, so as not to impose a specific bibliographic management software on all students. Since then, students have watched a short EndNote demonstration in class and optional 3-hour EndNote workshops in French (and later on in English) have been regularly scheduled for the students who would like to learn how to use EndNote.

With the increasing influx of English-only speaking students, it became obvious that the laboratories materials in English (guides, exercises, etc.) were insufficient for some of them. Therefore, the Graduate Studies Office decided that the ING6900 Research Methods course and laboratories would be provided in English, starting in Fall 2010.

\section{Timeline: A Credited Workshop for PhD Students Is Developed (2011)}

In the spring of 2011, the Graduate Studies Office asked the Library to develop a 10.5-hour workshop for PhD students, as part of a new complementary doctoral training program geared toward improving their skills in preparation for their academic and professional careers. This workshop was meant to replace the laboratories of the ING6900 course for the PhD students.

Consequently, the workshop CAP7005 Handling of Scientific and Technical Information pilot project started in Fall 2011, as a collaboration between the course coordinator - a professor at the Engineering Physics Department — and the librarians. This one-credit workshop consisted of four 3.5-hour sessions, three of which were given by the librarians and the fourth one by the 
workshop coordinator. The topics presented by the professor were the evaluation of doctoral students' information needs and the critical analysis of a scientific article.

CAP7005 was first offered to one group in French in Fall 2011 and then it became compulsory for all $\mathrm{PhD}$ students in Winter 2012, when it was offered in both French and English. Consequently, the course ING6900 Research Methods became mandatory only for Research Master's students.

In addition to the topics covered in ING6900 laboratories, CAP7005 focused on information sources for grey literature such as standards, patents, industrial catalogues, company directories, etc. Moreover, it was very important to the librarians to discuss and raise awareness of timely issues on scientific publishing, such as open access, and to make sure that the students had a clear understanding of plagiarism and copyright.

Whereas the ING6900 grade could influence the students' GPA, CAP7005 had no effect on it since it was graded on a pass/fail basis. Furthermore, since $\mathrm{PhD}$ students represented a heterogeneous clientele with an academic background that differed greatly from one student to another, it seemed important to help them assess their IL skills. Hence, two self-diagnostic tests have been developed. Participation in these tests allowed students to automatically obtain $20 \%$ of the final grade. Besides the open-book exam (40\% of the final grade), CAP7005 assessment also included three individual assignments, two graded by the librarians- "Description of a Research Topic" (5\%) and "Technical Intelligence" (10\%), and one graded by the professor- -Critical analysis of a scientific article" (25\%). The assignments allowed students to work on their own research project. This more personalized approach with an emphasis on students' individual research topic is considered to be better suited for graduate students [10].

Until Winter 2014, the professor taught the critical analysis of a scientific paper. In Fall 2014, at the professor's request, this part was transferred to the librarians, who have been in charge of all the pedagogical contents of the workshop ever since. However, at Polytechnique Montréal, only a professor can be the coordinator of a credited course or workshop. Thus, the professor remains in charge of the workshop, but he plays more of an advisory role and intervenes only in the event of a disagreement or specific problems, such as issues regarding grading.

ING6900 continued to be mandatory for Master's students and the midterm exam was replaced by three assignments that allowed students to work on their research topic.

\section{Timeline: Survey on Graduate Students Supervision (2012)}

In 2014, the results of a 2012 university-wide survey on graduate students' supervision, conducted at Polytechnique Montréal by the Pedagogical Support Office and the Graduate Studies Office, were published [25]. The survey had a very high response rate, both by graduate students $(37 \%)$ and by professors $(47 \%)$.

This survey was the follow-up to a similar survey conducted in 2001, right before the creation of the first IL credited course. The 2012 survey showed that $82.6 \%$ of students (almost $10 \%$ more than in 2001) recognized the importance of IL training. In both the 2001 and 2012 surveys, 77\% of professors stated it was important that students took IL classes [25]. According to these surveys, the students asked their research advisors for more help in all areas (study plans, 
bursaries, etc.) in 2012 compared to 2001, except for searching the literature, for which they needed less assistance from their advisors in 2012. The highest increase in students' satisfaction concerned the help they received on searching the literature, on choosing relevant publications, and on understanding scientific articles. The 2014 report specifically mentioned that these positive outcomes were linked to ING6900.

In 2016, the Polytechnique Montréal complementary doctoral training program, consisting of a series of one-credit workshops that included CAP7005, was awarded the Canadian Association for Graduate Studies' Award for Excellence and Innovation for Enhancing the Graduate Student Experience [26].

\section{Timeline: CAP7005 Becomes Mandatory for Research Master's Students and ING6900 Is Discontinued (Fall 2019)}

In 2019, the Graduate Studies Office decided that CAP7005 would be the only IL workshop offered to all graduate students and that ING6900 would be discontinued. The decision resulted in a new CAP7005 course analysis that slightly modified its assessment. The two self-diagnostic tests were merged into one (10\%) and the individual assignment "Search Strategy for Literature Review" (25\%) put more emphasis than before on creating and executing a complex search strategy to find references relevant to students' topics in an engineering bibliographic database. Regarding the pedagogical materials, the librarians needed to update the teaching contents of only one workshop, simplifying their tasks.

As seen in Figure 1 and as detailed previously, the training sessions have evolved significantly over time. Even though the training sessions have been called workshops, laboratories or courses, the terms "courses" or "training sessions" will be used from now on.

\section{Teaching Evaluation Surveys: Satisfaction Rates}

To improve the courses and to assess the participants' appreciation, students filled teaching evaluation surveys that contained two parts. An example of a full 2019 survey can be found in the appendix. In the first part, students were presented with statements related to the course objectives and statements related to the sessions themselves. For each statement, students used a rating scale from 1 (completely disagree) to 4 (completely agree) to indicate their degree of satisfaction. The statements included in the survey varied slightly over the years, especially before 2011, and some were included only at the PhD or Master's level. For the purpose of assessing the content of the workshop, answers to six statements, included in the survey since 2011 and shown in Table 1, were analyzed. Only survey results between Fall 2011 and Summer 2019 were included in the analysis since the content and format of the training sessions changed in 2011 with the creation of the CAP7005 workshop for PhD students, running in parallel with the ING6900 course for Master's students. For the purpose of this analysis, students enrolled in the CAP7005 workshop were considered PhD students, and those enrolled in the ING6900 course were considered Master's students, even though some $\mathrm{PhD}$ students were still enrolled in the ING6900 course in Fall 2011. 
Indicate to what degree you consider that each of the following objective was attained:

1. Define an information need related to a domain or applied to a research project.

2. Develop and optimize a search strategy by applying a bibliographic search method.

3. Identify information sources relevant to your field of research.

4. Recognize and respect the ethical and legal requirements associated with the use of information.

Indicate your degree of agreement with each of the following statement:

5. Sufficient time was allocated to reach the objectives of each session.

6. Generally, I improved my information research skills.

The evaluation surveys were distributed to students at the end of each course and were compiled by the Pedagogical Support Office. The results were returned electronically to each teaching librarian. However, some librarians do not work at the institution anymore and it was impossible to find their evaluation surveys. In part 1 of the surveys, responses from 1,731 students have been compiled since 2011 . This represents $59 \%$ of all the students who followed a credited course since that date. Table 2 shows how many surveys were accessible for each academic year, all courses combined. The number of evaluation surveys represents between $42 \%$ and $80 \%$ of all students enrolled in these courses in each academic year.

\section{Table 2. Number of surveys and percentage of students enrolled who answered}

\begin{tabular}{|c|c|c|}
\hline Academic year & Number of surveys & Response rate (\%) \\
\hline \hline $2011-2012$ & 246 & $67 \%$ \\
\hline $2012-2013$ & 149 & $44 \%$ \\
\hline $2013-2014$ & 144 & $44 \%$ \\
\hline $2014-2015$ & 223 & $63 \%$ \\
\hline $2015-2016$ & 234 & $67 \%$ \\
\hline $2016-2017$ & 230 & $67 \%$ \\
\hline $2017-2018$ & 318 & $80 \%$ \\
\hline $2018-2019$ & 187 & $42 \%$ \\
\hline \hline Total & 1,731 & $59 \%$ \\
\hline
\end{tabular}

In this analysis, students who agreed (answered "Partially agree" or "Completely agree") with a statement were considered as satisfied concerning this aspect of the course. The global satisfaction rate, all courses and years combined, is very high (Figure 3). To make comparison easier, these numbers are shown in terms of percentages. For each question, the percentage of satisfied students is over $90 \%$, the highest being $96.0 \%$ for statement 2 (Develop and optimize a search strategy by applying a bibliographic search method), and the lowest being $91.4 \%$ for statement 6 (Generally, I improved my information research skills). 


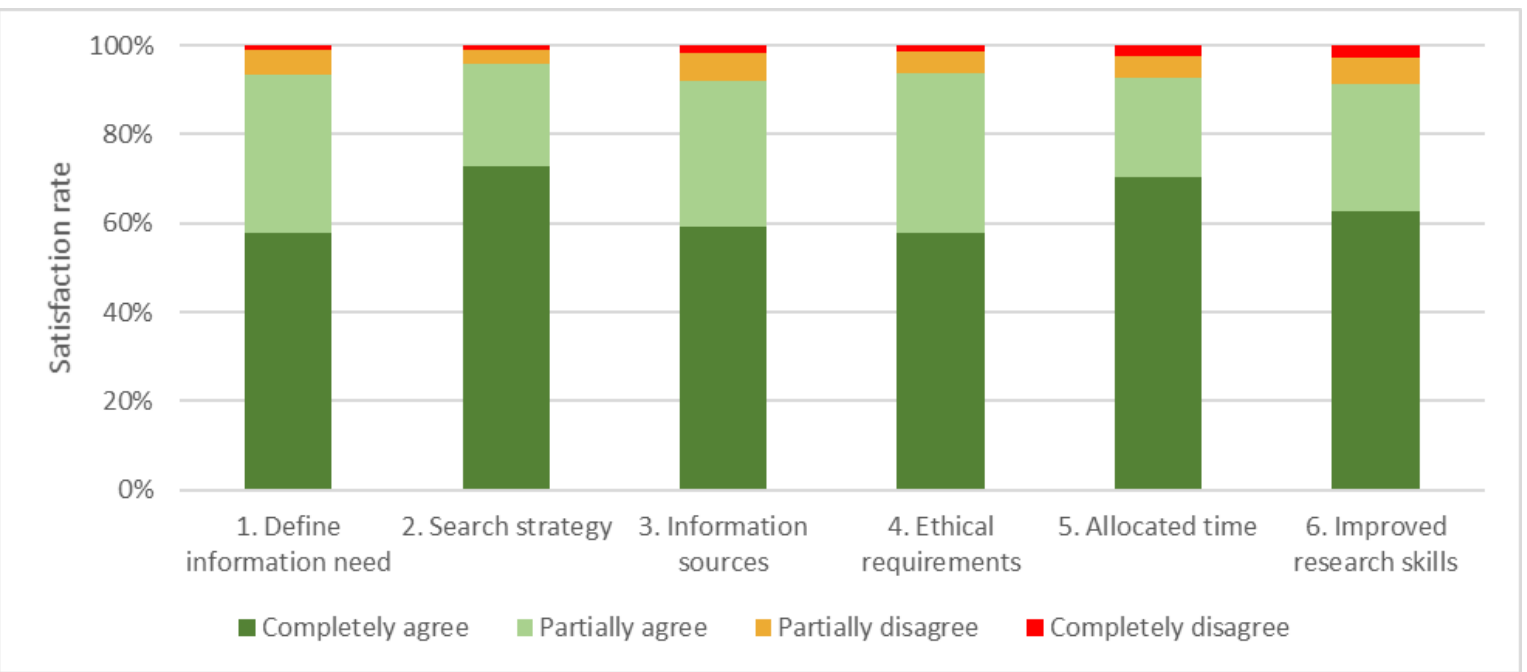

Figure 3. Satisfaction rate regarding the courses, all years, levels and languages combined (Fall 2011 to Summer 2019)

The influence of three factors were tested for each statement: evolution over time, influence of the language (French groups vs. English groups) and influence of level (PhD vs. Master's). To test the evolution over time, results from all groups from the same term were added and these percentages were compared. To test for the other two factors, results from groups differing by only one factor were compared for each statement. For example, to test the influence of language, the results from French PhD course for Winter 2012 were compared with the results from the English PhD course for the same term. These comparisons were made for all terms where appropriate data were available - 16 for the language factor and 13 for the level factor.

There is only one statement for which a single factor had an effect: PhD students were clearly more in agreement with statement 1 (Define an information need) than the Master's students. Out of the 13 comparisons for that statement, $\mathrm{PhD}$ students were more satisfied than the Master's students 9 times (with a satisfaction rate of $100 \%$ for each of those 9 comparisons). The satisfaction rate was similar three times and the $\mathrm{PhD}$ students were less satisfied only once.

This difference could be explained by the fact that less time was spent discussing the information needs during the training sessions at the Master's level. PhD students were asked to think about their own information needs and more examples were given throughout the workshop. With the integration of the Master's students in the CAP7005 workshop in Fall 2019, all graduate students now have a more complete presentation about information needs, so they should be more satisfied regarding this learning objective.

\section{Teaching Evaluation Surveys: Comments}

The second part of the survey consisted of three open-ended questions. Only the answers from the first question "What was the most important thing that you have learned during this workshop?" were analyzed in this article. The other two questions were less focused on assessing the content of the workshop. The comments suggesting course improvements were acknowledged after each course and addressed if they were in the librarians' capacities. For instance, several comments criticized the duration of the course, but the schedule has always 
been determined by the institution. The last question was very general and was often not filled in. This explains why these questions were not used in this analysis.

Contrary to the first part of the survey, the comment part was not returned electronically; the actual papers with the students' comments were given directly to each teaching librarian. Unfortunately, some papers have been lost and some are not identified with the term they were filled in, though they were all dated between Fall 2011 and Summer 2019. The language and the level were also known. The number of comments analyzed and the response rates between Fall 2011 and Summer 2019 are presented in Table 3.

Table 3. Number of surveys (comments section) analyzed and percentage of students enrolled in the training sessions who answered the surveys between Fall 2011 and Summer 2019

\begin{tabular}{|l|c|c|c|c|c|c|}
\cline { 2 - 7 } \multicolumn{1}{c|}{} & \multicolumn{2}{c|}{ French } & \multicolumn{2}{c|}{ English } & \multicolumn{2}{c|}{ Total } \\
\cline { 2 - 7 } & $\begin{array}{c}\text { Number of } \\
\text { surveys }\end{array}$ & $\begin{array}{c}\text { Response } \\
\text { rate (\%) }\end{array}$ & $\begin{array}{c}\text { Number of } \\
\text { surveys }\end{array}$ & $\begin{array}{c}\text { Response } \\
\text { rate (\%) }\end{array}$ & $\begin{array}{c}\text { Number of } \\
\text { surveys }\end{array}$ & $\begin{array}{c}\text { Response } \\
\text { rate (\%) }\end{array}$ \\
\hline PhD & 171 & $43.5 \%$ & 216 & $33.5 \%$ & 387 & $37.3 \%$ \\
\hline Master's & 421 & $27.0 \%$ & 71 & $21.8 \%$ & 492 & $26.1 \%$ \\
\hline Total & 592 & $30.4 \%$ & 287 & $29.6 \%$ & 879 & $30.1 \%$ \\
\hline
\end{tabular}

To analyze the answers, a content analysis method, as described by Huckin [27], was used. Considering that each teaching librarian read their comments after each course, they had a good idea of answers received over the years. This allowed for the creation of categories to use in this analysis. Each answer was then read and classified in the appropriate category. Even though the question was asking for only one element, some students gave more than one answer, so the answers to one question could be classified in more than one category. To ensure reliability, two different team members classified the same sample of 200 answers. Since each of these answers was assigned to very similar categories by both team members, it was decided to divide the rest of the 679 answers between the two members of the team. In the end, some categories containing very few answers were combined to create the "Other" category. Details of the final categories are given in Table 4. 
Table 4. Categories of comments

\begin{tabular}{|l|l|}
\hline $\begin{array}{l}\text { Categories - Most } \\
\text { important learning }\end{array}$ & \multicolumn{1}{|c|}{$\begin{array}{c}\text { Instructions for categorization - The answer was assigned to } \\
\text { this category when it was about: }\end{array}$} \\
\hline $\begin{array}{l}\text { Complex search } \\
\text { strategy }\end{array}$ & $\begin{array}{l}\text { Optimized strategy, Boolean operators, conceptual plan, classical } \\
\text { method, expert search, etc. }\end{array}$ \\
\hline $\begin{array}{l}\text { Information search - } \\
\text { global }\end{array}$ & Anything that means they improved their searching skills \\
\hline New tools & New tools, diversification of resources, discovery of databases, etc. \\
\hline $\begin{array}{l}\text { Name of a specific } \\
\text { source }\end{array}$ & $\begin{array}{l}\text { A specific resource was named: the Library website, a specific } \\
\text { database, etc. }\end{array}$ \\
\hline Keeping up to date & Subject alert, citation alert, following a journal, etc. \\
\hline Article analysis & Reading and analyzing a scientific article \\
\hline Plagiarism & How to cite, plagiarism, copyright, etc. \\
\hline Other & $\begin{array}{l}\text { Reference management, literature review, scientific communication } \\
\text { in general, searching for different types of documents (patents, } \\
\text { theses, standards...), open access, etc. }\end{array}$ \\
\hline
\end{tabular}

For all courses and years combined, the most common answer to the question "What was the most important thing that you have learned during this workshop?" is related to creating and performing a complex search strategy in specialized databases. This contradicts the idea that search queries using Boolean operators are not relevant anymore. According to this analysis, students found them useful.

Though the complex search strategy comes first, regardless of level or language, there were differences in the frequency of answers depending on these factors (see Figures 4 and 5).

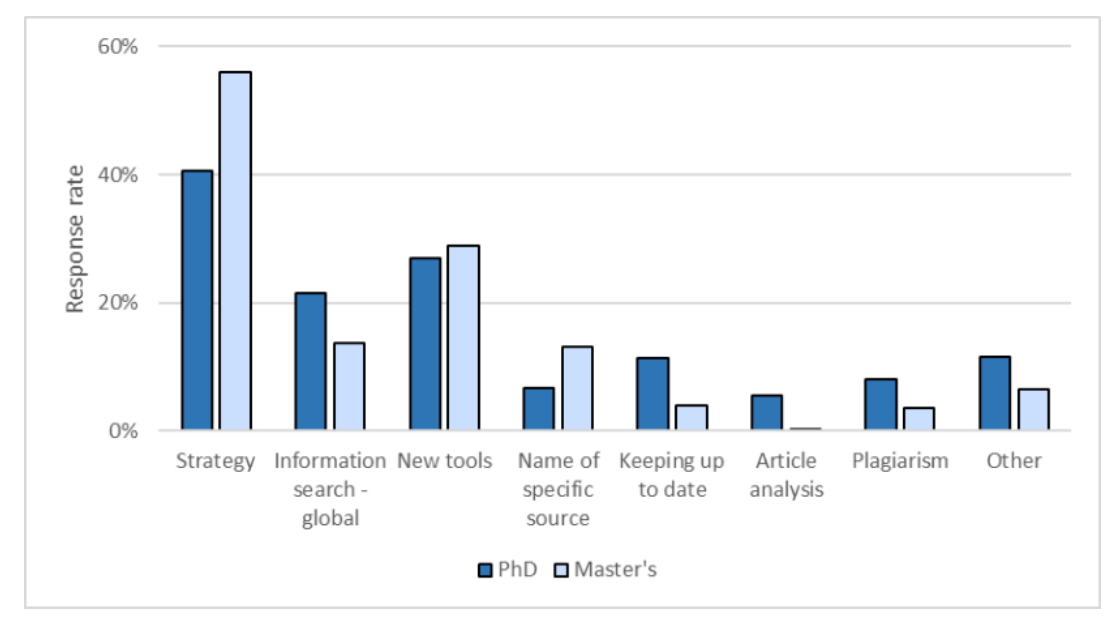

Figure 4. Response rates for each category of answers to the question "What was the most important thing that you have learned during this workshop?", by level, Fall 2011-Summer 2019 


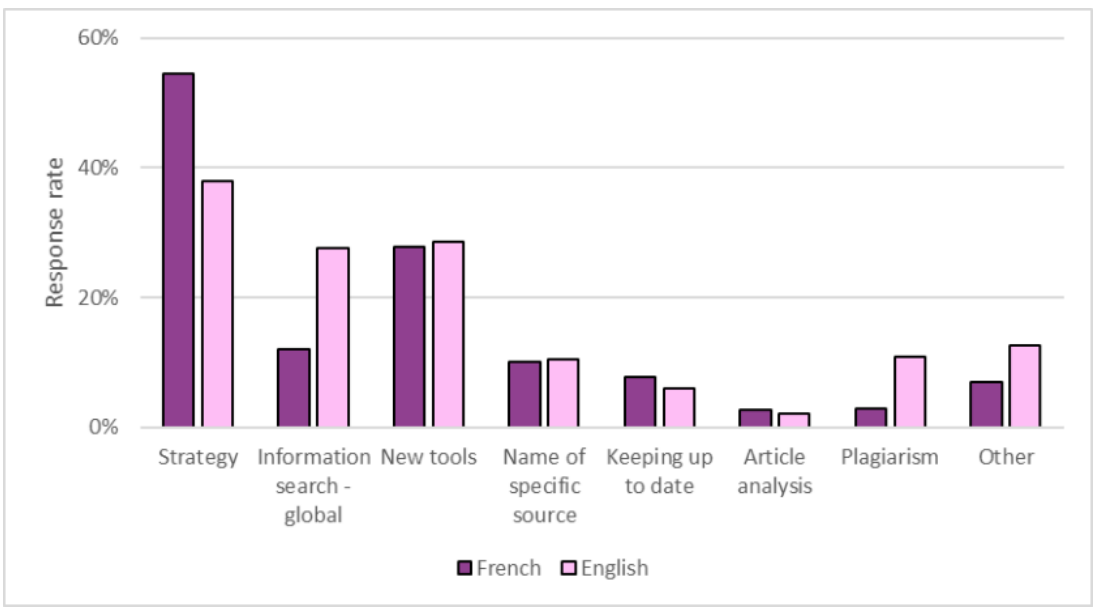

Figure 5. Response rates for each category of answers to the question "What was the most important thing that you have learned during this workshop?", by level, Fall 2011-Summer 2019

A higher percentage of Master's students (55.9\% vs. $40.6 \%$ of PhD students) thought the most important thing they learned was the complex search strategy (Figure 4). One explanation could be that more topics were covered in the doctoral training sessions, so $\mathrm{PhD}$ students had more possible answers. For example, 5.4\% of doctoral students mentioned article analysis as an important topic, but almost no Master's students mentioned it. It makes sense, since before the integration of Master's students in CAP7005 in Fall 2019, about one hour has been spent on article analysis at the doctoral level, and less than 10 minutes was spent on that subject at the Master's level. The higher percentage of $\mathrm{PhD}$ students answering that they globally improved their searching skills $(21.4 \%$ vs. $13.6 \%$ of Master's students $)$ could be due to the fact that many of the Master's students also completed their bachelor's at Polytechnique Montréal, where they already learned some basic IL skills. Consequently, what was important to them during the graduate IL course was to go beyond a general search for information, hence answering something related to the complex search strategy.

As for the influence of language (Figure 5), there is a difference between the French groups and the English groups. A higher percentage of French students (54.6\% vs. 38.0\%) mentioned the complex search strategy as the most important topic that they learned. Two complementary explanations are proposed. First, many of the students who took the English training sessions did not have English as a first language. When filling out the survey, they might have lacked the vocabulary to express specifically what they thought, so their answers were categorized as globally improving their searching skills. Also, many of these students came from abroad, where they might have had less training in information literacy. So, for some of them, just learning the basics of information searching was what was most important. These hypotheses could also explain the difference in frequency for the "Information search - global" category $(12.0 \%$ for French students vs. $27.5 \%$ for English students).

Another difference worth noting between the French and English groups is the percentages related to the category "Plagiarism" (2.9\% for French groups vs. 10.8\% for English groups). This could also be explained by the fact that many English students come from abroad. Citation practices and perception of what is considered plagiarism vary around the globe, so students coming from different countries find it very important to know about plagiarism in Canada, 
explaining the higher percentage. Most of the French students come from Québec or France and are already familiar with the definition of plagiarism as taught at Polytechnique Montréal so they did not mention it as often.

\section{Discussion}

Eighteen years after their creation, the mandatory credited IL courses for graduate students at Polytechnique Montréal have been a success story made possible by multiple factors. Indeed, the importance of managing information and literature has been recognized by the University as one of the five important skills to develop in PhD or Research Master's programs [28]. In the early 2000s, professors were aware of the potential contribution of librarians in students acquiring this skill, as reflected by their request for the creation of training sessions for graduate students. Usually, support by faculty is seen as a good starting point for realizing a project in a university. Later on, in the early 2010s, professors still supported the relevance of these sessions as shown by the university-wide survey [25]. Their support in this period was critical, as a global reflection concerning complementary skills training, including IL, was taking place in the institution. This reflection led to the creation of a complementary doctoral training program for $\mathrm{PhD}$ students, which included CAP7005.

As explained in the Timeline, the team of teaching librarians has made several essential adaptations to the courses in order to better meet the students' needs. These needs were sometimes expressed through institutional requests, mostly regarding the language and the targeted clientele, whereas at other times they were noticed and addressed by the librarians themselves. Changes made to the assessments are a good example of the latter. After the portfolio was replaced by exams for logistical reasons, the librarians knew that assignments related to students' projects would be more useful and stimulating for them. As a solution, librarians brought back parts of the assignments as hands-on exercises in which students were asked to develop a sound search strategy for finding scientific articles linked to their research subject. By doing these assignments, students better saw the relevance of the course and felt that the time invested was not just to obtain the credit, but had value for their research project. This focus on their project in the complementary doctoral training program might have encouraged them to persevere in obtaining their degree.

Other important adaptations made by the librarians included the integration of various techniques of active pedagogy in order to ensure that some important notions were fully understood and applied. In this regard, the pedagogical skills of the librarians have been useful. Indeed, three librarians possess a teaching degree or certificate and all librarians share a keen interest in the most recent trends in pedagogy.

The approval by the University of all changes proposed over the years by the librarians implies a certain level of satisfaction towards these credited IL training sessions. Moreover, considering that improving the retention rate for graduate students is also important for universities, it is likely that high satisfaction rates by students, as shown in the analysis of the teaching evaluation survey, contributed to the support received from the university.

The positive impacts of the sessions were numerous, for students, for the Library and its employees, and for the University. Students were the main beneficiaries of IL training sessions. 
Indeed, in addition to a high level of satisfaction, the evaluation surveys show that a large proportion of participating students said that performing a complex search strategy for finding scientific articles in specialized databases was the most important aspect they learned. Having students execute these searches for their own research subjects maximize the chances that they read articles from a variety of information sources and that they do not limit their searches to Google Scholar. This could lead to more efficient information search habits and more thorough literature reviews that can contribute to enhancing the quality of research produced by the University. Consequently, the training sessions contribute to achieving the University learning objectives for graduate students in research programs.

In addition, a few students wrote in the evaluation surveys how those learnings were already or would be useful to them. A student specifically mentioned that the sessions helped "save time in conducting the literature review and optimize the use of the Library website". Some other students also indicated that the sessions would result in time savings for them, which is valuable not only for them, but also for the institution. Another student revealed that alerts were already providing relevant articles for their research. Another comment said "Thank you 1000 times for this workshop that is for me the key to success in the academic field". These comments, a few among many others, are consistent with previous statements about the positive impact of the courses on graduate students.

The IL training sessions have also had a significant effect on the Library itself. Considering that these sessions take place in the computer lab located inside the Library, all enrolled students physically had to come to the Library and some of them discovered it for the first time. Moreover, as shown in the "Teaching Evaluation Surveys: Comments" section, a significant proportion of students said that learning about Library resources and tools that were previously unknown to them was much appreciated. As the IL training has been going on for 18 years, it is impossible to compare usage statistics of the databases before the training began with current statistics. However, using these resources during the sessions and producing the assignments generated some basic usage of the Library main specialized databases such as Compendex, Inspec, and Web of Science. In addition, since elaborating a complex search strategy for finding articles in specialized databases is the most important element a high proportion of students mentioned learning during the course, it can be assumed that many students are likely to continue using them afterwards.

By meeting and interacting with students, the teaching librarians also benefit significantly from these training sessions. They learn about the research projects conducted at the university by reading students' assignments. This facilitates discussions with professors and other university employees when answering different types of requests. As they update the course materials each semester, librarians can discover new features of resources that could serve researchers' needs. Addressing certain topics during class and answering students' questions also help librarians to stay up to date with the transformation of the scientific publishing landscape.

As the perception of librarians' roles in academic libraries have changed significantly over the last decades, librarians from Polytechnique Montréal are no exception. In fact, the typical requirements in librarian recruitment changed over the last few years. Teaching experience or pedagogical training, while not mandatory, is considered an asset when hiring librarians at Polytechnique Montréal. For instance, all interviews for librarians that are likely to teach classes 
now include a short demonstration of IL training in both English and French. As a result, the pedagogical skills and the level of fluency in English language of Polytechnique librarians, who are typically French speaking, increased in recent years.

\section{Conclusion}

The purpose of this paper is to share with the scientific community the librarians' experience in creating and maintaining a credited and mandatory IL training for graduate students. The decision to provide a single course to all graduate students since Fall 2019 could lead to some new challenges considering that these students' basic IL knowledge tends to differ significantly. It would be interesting to see if some changes will be required in the pedagogical approaches and how this will affect the feedback received in future evaluation surveys. In 2020, a survey will be conducted in order to learn about professors' perception of the improvements in the IL skills of the students they supervise.

\section{Acknowledgments}

The authors would like to acknowledge the contribution of Olivier Dufault, Amanda Riddles, and Patrick Desjardins, Full Professor, Department of Engineering Physics. 


\section{References}

[1] Polytechnique Montréal, "Polytechnique by the numbers," Pamphlet, 2019.

[2] Polytechnique Montréal, "Statistiques officielles des personnes inscrites au trimestre d'automne 2019," 2019.

[3] Association of College \& Research Libraries, "Information literacy competency standards for higher education," 2000. [Online]. Available: http://www.ala.org/acrl/standards/ilframework

[4] Association of College \& Research Libraries, "Framework for information literacy for higher education," 2015. [Online]. Available:

http://www.ala.org/acrl/standards/ilframework

[5] S. J. Behrens, "A conceptual analysis and historical overview of information literacy," College \& Research Libraries, vol. 55, no. 4, pp. 309-322, 1994, doi: 10.5860/crl_55_04_309.

[6] American Library Association, "Presidential Committee on Information Literacy: Final report," 1989. [Online]. Available: http://www.ala.org/acrl/publications/whitepapers/presidential

[7] M. M. England, "Information literacy for engineers: The problem and its solution," in 33rd Aerospace Sciences Meeting and Exhibit, Reno, NV, January 9-12, 1995. [Online]. Available: https://doi.org/10.2514/6.1995-705

[8] L. L. Tafel, "Overview of the literature on bibliographic instruction in engineering," in ASEE Annual Conference, Henrietta, NY, June 19-23, 1983, pp. 819-823.

[9] S. Polkinghorne and H. Julien, "Treading water: Results from the longitudinal study of information literacy instruction in Canadian academic libraries, 1995-2017," Canadian Journal of Information and Library Science, vol. 42, no. 1-2, pp. 69-93, 2018. [Online]. Available: https://muse.jhu.edu/article/717388/summary.

[10] C. S. Harris, "The case for partnering doctoral students with librarians: A synthesis of the literatures," Library Review, vol. 60, no. 7, pp. 599-620, 2011, doi: 10.1108/00242531111153614.

[11] K. Hoffman, F. Antwi-Nsiah, V. Feng, and M. Stanley, "Library research skills: A needs assessment for graduate student workshops," Issues in Science \& Technology Librarianship, no. 53, 2008, doi: 10.5062/F48P5XFC.

[12] D. Gibbs, J. Boettcher, J. Hollingsworth, and H. Slania, "Assessing the research needs of graduate students at Georgetown University," The Journal of Academic Librarianship, vol. 38, no. 5, pp. 268-276, 2012, doi: 10.1016/j.acalib.2012.07.002.

[13] J. C. Zhao, "Making information literacy instruction relevant: A needs assessment approach at McGill University," Science \& Technology Libraries, vol. 34, no. 3, pp. 241256, 2015, doi: 10.1080/0194262X.2015.1089815.

[14] S. Kumar, M. Ochoa, and M. Edwards, "Considering information literacy skills and needs: Designing library instruction for the online learner," Communications in Information Literacy, vol. 6, no. 1, pp. 91-106, 2012, doi: 10.15760/comminfolit.2012.6.1.120.

[15] H. G. Rempel and J. Davidson, "Providing information literacy instruction to graduate students through literature review workshops," Issues in Science \& Technology Librarianship, no. 53, 2008, doi: 10.5062/F44X55RG. 
[16] L. Saunders, J. Severyn, S. Freundlich, V. Piroli, and J. Shaw-Munderback, "Assessing graduate level information literacy instruction with critical incident questionnaires," The Journal of Academic Librarianship, vol. 42, no. 6, pp. 655-663, 2016. [Online]. Available: http://www.sciencedirect.com/science/article/pii/S0099133316301446.

[17] L. M. Dyckman, "Fear of failure and fear of finishing: A case study on the emotional aspects of dissertation proposal research, with thoughts on library instruction and graduate student retention," in ACRL Twelfth National Conference, Minneapolis, MN, April 7-10, 2005, vol. 1, pp. 351-362. [Online]. Available: http://www.ala.org/acrl/sites/ala.org.acrl/files/content/conferences/pdf/dyckman05.pdf.

[18] H. Julien and S. Boon, "Assessing instructional outcomes in Canadian academic libraries," Library \& Information Science Research, vol. 26, no. 2, pp. 121-139, 2004. [Online]. Available: http://www.sciencedirect.com/science/article/pii/S0740818804000222.

[19] M. Talikka, H. Eskelinen, and H. Varri, "Does IL education have an impact on undergraduate engineering students' research skills?," in IATUL 35th Annual Conference, Espoo, Finland, Jun 2-5, 2014, no. 35, pp. 1-11. [Online]. Available: https://docs.lib.purdue.edu/cgi/viewcontent.cgi?article=2039\&context=iatul.

[20] J.-M. Cook, "A library credit course and student success sates: A longitudinal study," College \& Research Libraries, vol. 75, no. 3, pp. 272-283, 2014, doi: 10.5860/crl12-424

[21] M. O'Kelly, "Correlation between library instruction and student retention," in Southeastern Library Assessment Conference, Atlanta, GA, 2015. [Online]. Available: https://scholarworks.gvsu.edu/cgi/viewcontent.cgi?article=1056\&context=library_present ations.

[22] N. Clairoux, S. Desbiens, M. Clar, P. Dupont, and M. St-Jean, "Integrating information literacy in health sciences curricula: A case study from Québec," Health Information \& Libraries Journal, vol. 30, no. 3, pp. 201-211, 2013, doi: 10.1111/hir.12025 1471-1834.

[23] Polytechnique Montréal, "Recherche et développement, Principe 3, Objectif 3D-6," in Plan d'action 1999-2003 de l'École Polytechnique: Stratégies, Cahier de suivi, 2000.

[24] M. Proulx and H. Mallet, "La création, l'implantation et l'évolution d'un cours crédité obligatoire de formation documentaire aux cycles supérieurs à l'École Polytechnique: La réalité d'un succès," Argus, vol. 35, no. 2, pp. 17-23, 2006.

[25] J. Dansereau, L. Forest, M.-È. Plamondon, and D. Villiard, Sondage sur l'encadrement des étudiants aux cycles supérieurs à Polytechnique Montréal: Rapport d'analyse. Polytechnique Montréal, Montréal, 2014.

[26] Canadian Association for Graduate Studies, "Winning program incorporates work skills into curriculum," 2016. [Online]. Available: https://cags.ca/prizes/winning-programincorporates-work-skills-into-curriculum/

[27] T. Huckin, "Content analysis: What texts talk about," in What Writing Does and How It Does It: An Introduction to Analyzing Texts and Textual Practices, C. Bazerman and P. Prior Eds. New Jersey, NJ: Lawrence Erlbaum Associates, 2004.

[28] Polytechnique Montréal, "Compétences, éléments de compétences et ressources à mobiliser pour le DESS, la maitrise professionnelle, la maîtrise recherche et le doctorat," 2014. 


\title{
Appendix - Example of a full evaluation survey
}

\author{
Assessment of Workshop Teaching \\ CAP7005E - Handling of Scientific and Technical Information \\ Summer 2019
}

\section{PURPOSE OF THE SURVEY}

In order to improve CAP7005E (sessions 1 to 4), we would like to have your opinion on various aspects of this workshop.

\begin{tabular}{|c|c|c|c|}
\hline $\begin{array}{c}\text { Group } \\
\mathbf{0 1}\end{array}$ & Wednesday & $9: 00-12: 15$ p.m. & Name of teaching librarians \\
\hline
\end{tabular}

\section{GUIDELINES}

The overall results of this anonymous evaluation will be given to the librarians and to the professor responsible for the workshop only after the final grades have been assigned.

Answer to each of the following statements individually, using the rating scale provided below:

$\begin{array}{lll}\text { Enter } & \mathbf{4} & \text { if you completely agree with the statement } \\ \text { Enter } & \mathbf{3} & \text { if you partially agree with the statement } \\ \text { Enter } & \mathbf{2} & \text { if you partially disagree with the statement } \\ \text { Enter } & \mathbf{1} & \text { if you completely disagree with the statement } \\ \text { Enter } & \mathbf{X} & \text { if you do not know what to answer or if the statement does not apply }\end{array}$

\section{WORKSHOP OBJECTIVES}

For each of the following objectives, indicate to what degree you consider that the objective was attained.

1. Define an information need related to a domain or applied to a research project.

2. Develop and optimize a search strategy by applying a bibliographic search method.

3. Identify information sources relevant to your field of research.

4. Recognize and respect the ethical and legal requirements associated with the use of information.

5. Set up useful and pertinent monitoring activities in order to stay up to date.

6. Apply basic principles in order to analyze the contributions and the limitations of a scientific article.

\section{WORKSHOP SESSIONS}

7. The objectives of the workshop sessions were clearly stated.

8. Overall, the sessions corresponded to the workshop outline.

9. Sufficient time was allocated to reach the objectives of each session.

10. Generally, I improved my information research skills. 


\section{COMMENTS}

11. What was the most important thing that you have learned during this workshop?

12. In your opinion, are there any improvements necessary to the workshop sessions? If so, what are they?

13. Other comments and suggestions. 